\title{
ACQUISITION OF HEROIN CONDITIONED IMMUNOSUPPRESSION REQUIRES IL-1 SIGNALING IN THE DORSAL HIPPOCAMPUS
}

\author{
Christina L. Lebonville
}

A thesis submitted to the faculty at the University of North Carolina at Chapel Hill in partial fulfillment of the requirements for the degree of Master of Psychology and Neuroscience in the Behavioral Neuroscience program in the College of Arts and Sciences.

Chapel Hill

2016

Approved by:

Donald T. Lysle

Regina M. Carelli

Todd E. Thiele 
(C) 2016

Christina L. Lebonville ALL RIGHTS RESERVED 


\begin{abstract}
Christina L. Lebonville: Acquisition of Heroin Conditioned Immunosuppression Requires Il-1 Signaling in the Dorsal Hippocampus (Under the direction of Donald T. Lysle)
\end{abstract}

Opioid users experience increased infection rates. While partially attributable to direct opiate-immune interactions, conditioned immune responses contribute as well. Neural circuitry governing opioid conditioned immune responses has been investigated, but mediating mechanisms are unknown. Previous studies showed that hippocampal IL-1 signaling is required for expression of heroin conditioned immunosuppression following learning. Current studies were designed to further characterize hippocampal IL-1's role in this phenomenon by manipulating IL-1 during learning. Experiment 1 tested whether hippocampal IL-1 is required for the acquisition of heroin conditioned immunosuppression. Experiment 2 tested whether hippocampal IL-1 is required for unconditioned heroin immunosuppression. Blocking IL-1 signaling in the dorsal hippocampus with IL-1RA during each conditioning session, but not on interspersed non-conditioning days, attenuated the acquisition of heroin conditioned immunosuppression. IL-1RA treatment did not alter unconditioned immunosuppression to a single dose of heroin. Thus, IL-1 signaling may play a role in learning the association between heroin and context. 
To my partner Steven Lebonville, your support and encouragement is worth more than you know.

Thank you for being my family. 


\section{ACKNOWLEDGEMENTS}

Many thanks to my laboratory colleagues, Meghan E. Jones, Letty B. Cooper, Lee W.

Hutson, and Rita. A. Fuchs, and mentor, Donald T. Lysle, whose guidance and editing were instrumental in completing these experiments and writing this thesis. 


\section{TABLE OF CONTENTS}

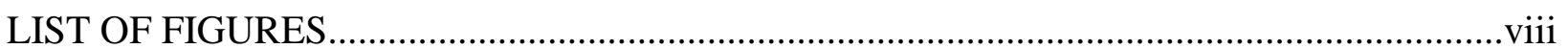

LIST OF ABBREVIATIONS..............................................................................................

CHAPTER 1: ACQUISITION OF HEROIN CONDITIONED IMMUNO-

SUPPRESSION REQUIRES IL-1 SIGNALING IN THE DORSAL

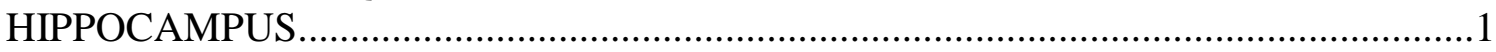

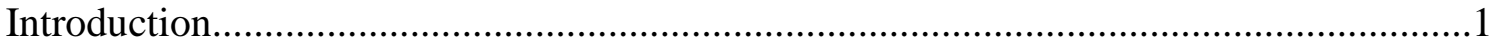

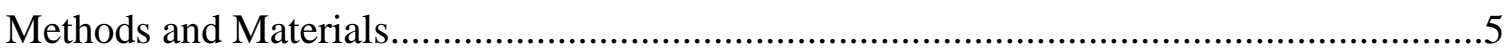

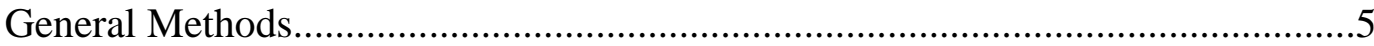

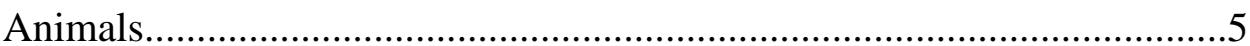

Drugs \& Delivery.....................................................................................

Surgical Procedure

Conditioning Procedure............................................................................

Tissue Collection......................................................................................

RNA Extraction \& RT-qPCR...............................................................

Protein Extraction/Quantification \& iNOS ELISA.......................................

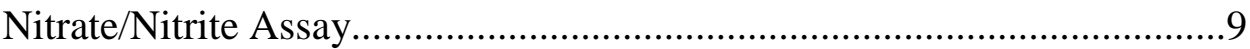

Histology

Statistical Analysis.................................................................................10

Experiment Specific Procedures..........................................................................11

Experiment 1: IL-1RA Antagonism During Acquisition of Heroin Conditioned Immunosuppression...............11 
Experiment 2: IL-1RA Antagonism During Heroin Unconditioned Immunosuppression............................................12

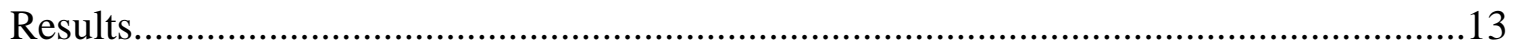

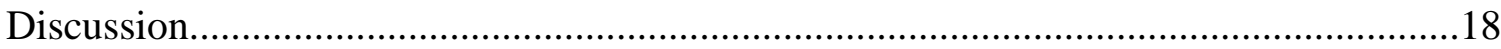

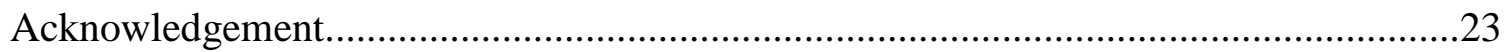

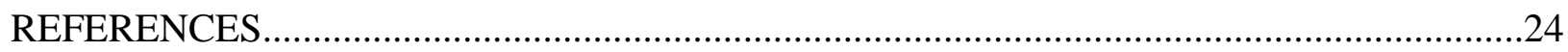




\section{LIST OF FIGURES}

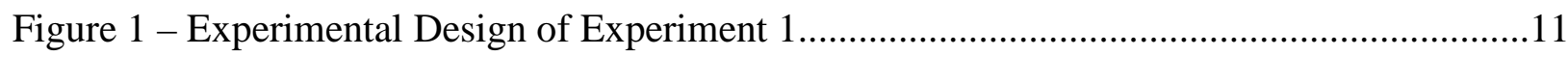

Figure 2 - Experimental Design of Experiment 2.........................................................13

Figure 3 - Immune suppression to CS is attenuated by IL-1 signaling

blockade before conditioning with heroin..............................................................14

Figure 4 - Immune suppression to heroin is not attenuated by IL-1

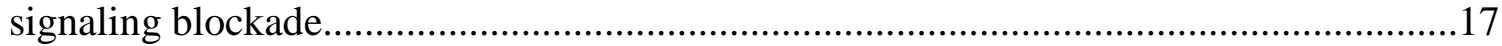




\section{LIST OF ABBREVIATIONS}

$\begin{array}{ll}\text { ANOVA } & \text { analysis of variance } \\ \text { CS } & \text { conditioned stimulus } \\ \text { CR } & \text { conditioned response } \\ \text { DH } & \text { dorsal hippocampus } \\ \text { ELISA } & \text { enzyme-linked immunosorbent assay } \\ \text { HC } & \text { home cage } \\ \text { HSD } & \text { Honestly Significant Difference } \\ \text { IACUC } & \text { Institutional Animal Care and Use Committee } \\ \text { IL-1 } & \text { interleukin-1 } \\ \text { IL-1 } \beta & \text { interleukin-1 } \beta \\ \text { IL-1R1 } & \text { IL-1 receptor 1 } \\ \text { IL-1RA } & \text { interleukin-1 receptor antagonist } \\ \text { iNOS } & \text { inducible nitric oxide } \\ \text { LPS } & \text { lipopolysaccharide } \\ \text { LTP } & \text { long-term potentiation } \\ \text { NO } & \text { nitric oxide } \\ \text { US } & \text { reverse transcription quantitative real-time PCR } \\ \text { HCR } & \end{array}$




\section{CHAPTER 1: ACQUISITION OF HEROIN CONDITIONED IMMUNOSUPPRESSION REQUIRES IL-1 SIGNALING IN THE DORSAL HIPPOCAMPUS ${ }^{1}$}

\section{Introduction}

Opioid users show an increased incidence of infections (Govitrapong et al., 1998; Louria et al., 1967; Risdahl et al., 1998), the treatment of which imposes a large economic burden (Mark et al., 2001). These infections are not simply due to increased pathogen exposure from intravenous drug use, but may also be attributed to opiates' interaction with the immune system (Horsburgh et al., 1989; Simonovska et al., 2011; Vallejo et al., 2004). Furthermore, while opioids on their own hinder the body's ability to respond to disease and infection, these immunosuppressive properties can become conditioned. Repeated presentations of immune modulators, like opioids, with predictive stimuli can result in Pavlovian conditioning of immune system function, allowing for these stimuli to later affect the immune system in the same way as the modulators themselves [for review (Schedlowski and Pacheco-Lopez, 2010)]. Therefore, exposure to opioid-associated environments or stimuli might then lead to an exacerbation of immunological vulnerability in opioid users.

Conditioned immune responses have been demonstrated in rodent models using stimuli paired with distinct immunosuppressive agents such as cyclophosphamide (Ader, 1974; Ader and Cohen, 1975), cyclosporine A (Exton et al., 2001; Exton et al., 1998a; Exton et al., 1998b; von Horsten et al., 1998), foot shock stress (Lysle et al., 1988; Perez and Lysle, 1995), cocaine

\footnotetext{
${ }^{1}$ This chapter previously appeared as an article in the journal Brain, Behavior, and Immunity. The original citation is as follows: Lebonville, C.L. et. al. 2016. Acquisition of Heroin Conditioned Immunosuppression Requires IL-1 Signaling in the Dorsal Hippocampus. Brain, Behav., and Imm. In Press.
} 
(Kubera et al., 2008), morphine (Coussons-Read et al., 1994a, b; Coussons et al., 1992; Luecken and Lysle, 1992), and heroin (Lysle and Ijames, 2002; Szczytkowski et al., 2011; Szczytkowski and Lysle, 2007, 2008, 2010).

Heroin conditioned immune effects are of particular concern due to recent rises in heroin’s use (United States. Substance Abuse and Mental Health Services Administration, 2014). The NIH attributes this rise to the near tripling of opioid prescriptions in order to treat pain in the last decade that may have led many to turn to heroin as a cheaper alternative to costly pain medication (United States. National Institute on Drug Abuse, 2014). With opioid use, including heroin, on the rise, it becomes more important than ever to understand the immune consequences of their use and the neural mechanisms governing the classical conditioning that may increase the severity or duration of these consequences.

Like other forms of immune conditioning, which have been primarily studied within the context of placebo effects [for review (Schedlowski et al., 2015)], opioid immune conditioning is centrally mediated (Fecho et al., 1996; Lysle et al., 1996) and depends on learned associations between a conditioned stimulus (CS) and opioids, as unconditioned stimuli (US). After multiple pairings of the CS and the US, the CS itself becomes able to evoke a conditioned response (CR) similar to the effects of opioids themselves (Lysle and Ijames, 2002). For example, a single injection of heroin has been shown to suppress measures of nitric oxide (NO) (Lysle and How, 2000), an important part of the immune system released by multiple immune cells that conveys resistance to infection and serves as a regulator of immune function (Bogdan, 2001; Lewis et al., 2010; MacMicking et al., 1995; Nathan and Shiloh, 2000; Uehara et al., 2015). Its expression is potently and widely induced by lipopolysaccharide (LPS), a component of gram negative bacterial walls. NO production can be indirectly measured by levels of inducible nitric oxide 
(iNOS), the enzyme responsible for producing NO, and nitrate/nitrite, byproducts of NO degradation in the blood.

Previous studies have taken advantage of LPS's potent induction of NO to investigate heroin's immune effects (Lysle and How, 2000). The effects of heroin on LPS-induced NO are also able to be conditioned to heroin-associated stimuli. Pairing heroin (US) with a distinct environmental context (CS) allows the heroin-paired context to evoke a CR in rats in that the exposure to the context alone will cause conditioned suppression of NO (Lysle and Ijames, 2002; Szczytkowski et al., 2011; Szczytkowski et al., 2013; Szczytkowski and Lysle, 2007, 2008, 2010). Research using this model has demonstrated that the basolateral amygdala, nucleus accumbens (Saurer et al., 2009; Szczytkowski and Lysle, 2008), and a circuit comprised of these regions and the ventral tegmental area is necessary for the expression of heroin conditioned immunosuppression (Szczytkowski et al., 2011). More recently, the hippocampus, a brain region heavily implicated in contextual learning (Maren and Holt, 1999; Phillips and Ledoux, 1994; Redish, 2001) has also been shown to be involved in the expression of heroin conditioned immunosuppression. Inactivation of the dorsal hippocampus (DH) using a GABA agonist cocktail, baclofen/muscimol, or knockdown of interleukin-1 $\beta$ (IL-1 $\beta$ ) signaling within the DH just before testing prevented a heroin-paired context from suppressing the immune response to LPS (Szczytkowski et al., 2013). This not only suggests the requirement of the DH for the expression of heroin conditioned immunosuppression, but also implicates a novel role for brain IL-1 $\beta$ in this effect.

IL-1 $\beta$ is a pro-inflammatory cytokine that has been linked to learning and memory. Studies suggest this cytokine is induced in the DH by Pavlovian conditioning (Goshen et al., 2007), is required for the maintenance of long-term potentiation (LTP) (Schneider et al., 1998), and causes disruption of normal memory at either supra- or sub-optimal expression levels (Avital 
et al., 2003; Ben Menachem-Zidon et al., 2011; Goshen et al., 2007; Griffin et al., 1989; Ross et al., 2003; Schmid et al., 2009; Schneider et al., 1998). Furthermore, IL-1 seems to play a key role in memory within the hippocampus as IL-1 manipulations specifically affect hippocampaldependent memory but not hippocampal-independent memory [for review (Lynch, 2015)], and levels of IL-1 receptor in the hippocampus are particularly high [see (Schneider et al., 1998)].

Given that IL-1 in the hippocampus is important for the expression of heroin conditioned immunosuppression, it is yet to be determined if hippocampal IL-1 is also required for the encoding of immune associations during acquisition. Therefore, in the present studies, Experiment 1 sought to investigate whether hippocampal blockade of the most well-studied receptor for IL-1, IL-1 receptor 1 (IL-1R1), could interfere with the acquisition of heroin conditioned immunosuppression.

Many studies suggest that the CR is specific to and mimics the effects of the US [see (Schedlowski et al., 2015)], which may suggest that the neural pathways engaged during the expression of a CR recapitulate those engaged by the US. In the context of our model, it is unknown whether IL-1 signaling is required for heroin's immunosuppressive effects. If IL-1 in the dorsal hippocampus is specifically required for memory processes engaged in connecting the immune effects of the US to the CS, then blockade of IL-1 signaling in the dorsal hippocampus will not interfere with the immunosuppressive response to a heroin US. Experiment 2 investigated the possibility that IL-1 in the dorsal hippocampus has a distinguishable role in associative learning and not in mediating the unconditioned response to the US.

The present studies will critically inform our understanding of how stimuli-drug associations engage memory and immune systems, possibly providing therapeutic targets to aid in the prevention of the negative health consequences associated with opioid use. 


\section{Methods and Materials}

\section{General Methods}

Animals. Adult, male Lewis rats $(\mathrm{N}=55)$ weighing $225-250$ g were purchased from Charles-River Laboratories (Raleigh, NC). Animals were housed individually in a colony room under a reversed 12-hour day-night cycle, with ad libitum access to food and water. Animals received at least 12 days of habituation before experimentation and were handled regularly during this time. All procedures were approved by the Institutional Animal Care and Use Committee (IACUC) of the University of North Carolina at Chapel Hill and conformed to the National Research Council's Guide for the Care and Use of Laboratory Animals (Institute for Laboratory Animal Research Division of Earth and Life Studies).

Drugs \& Delivery. Heroin (diacetylmorphine) was obtained from NIDA’s Drug Supply System (Bethesda, MD) and was dissolved in $0.9 \%$ sterile saline to a final concentration of 1.0 $\mathrm{mg} / \mathrm{mL}$. Throughout conditioning, heroin solutions were stored at $4^{\circ} \mathrm{C}$. Heroin-filled syringes were allowed to come to room temperature prior to injections. Rats were injected subcutaneously with $1.0 \mathrm{mg} / \mathrm{kg}$ heroin, a dose chosen based on prior experiments in our laboratory showing that this dosage alters LPS-induced iNOS mRNA expression in the spleen (Lysle and How, 2000, Lysle and Ijames, 2002, Szczytkowski and Lysle, 2007). Lipopolysaccharide (LPS) was injected subcutaneously at a concentration of $1 \mathrm{mg} / \mathrm{kg}$ (derived from E. coli, serotype 055:B5, dissolved in sterile, pyrogen-free saline), a dose which induces sickness behavior and produces reliable induction of nitric oxide measures. This particular serotype has been used previously in our laboratory to investigate immune responses following heroin conditioning, an important verification due to the differing activity between LPS serotypes even from within the same species (Caroff et al., 2002). Human recombinant interleukin-1 receptor antagonist (IL-1RA) (Genscript, Piscataway, NJ, Catalog No: Z00367) was reconstituted in 0.9\% sterile saline to a 
final concentration of $2.5 \mu \mathrm{g} / \mu \mathrm{L}$. Reconstituted IL-1RA was then aliquoted and stored at $-20^{\circ} \mathrm{C}$. Rats were intracranially infused with $1.25 \mu \mathrm{g}$ in $0.5 \mu \mathrm{L}$ volume per hemisphere into the dorsal hippocampus (DH) over 2 minutes at a constant rate of $0.25 \mu \mathrm{L} / \mathrm{min}$. Thereafter, the injectors were allowed to sit for 1 additional minute to allow for proper diffusion from the injection site. At least 48 hours prior to intracranial drug infusion into the $\mathrm{DH}$, injectors were lowered into the cannulae and the rats were handled to habituate them to the infusion procedures. Just prior to infusion, frozen IL-1RA aliquots were thawed on ice, briefly centrifuged, and stored on ice throughout. Vehicle infusions were of $0.9 \%$ sterile saline.

Surgical Procedure. Animals were anesthetized with $1.0 \mathrm{~mL} / \mathrm{kg}$ intraperitoneally injected 9:1 (vol:vol) ketamine hydrochloride $(100 \mathrm{mg} / \mathrm{mL})$ and xylazine $(100 \mathrm{mg} / \mathrm{mL})$. Surgically prepared animals were placed into the stereotaxic apparatus where guide cannula (26gauge, Plastics One, Roanoke, VA) were directed bilaterally toward the DH with coordinates AP $-3.4 \mathrm{~mm}, \mathrm{ML} \pm 3.1 \mathrm{~mm}, \mathrm{DV}-2.2 \mathrm{~mm}$, relative to bregma; $15^{\circ}$ angle laterally (Paxinos and Watson, 1998). Animals were given at least 13 days for post-operative recovery during which they were handled and monitored regularly.

Conditioning Procedure. Rats received five, 60-min conditioning sessions every other day as in prior studies, which has been shown to be sufficient to generate conditioned immunosuppression to the heroin-paired context (Szczytkowski et al., 2011; Szczytkowski et al., 2013; Szczytkowski and Lysle, 2010). Each conditioning session involved heroin administration (US) immediately followed by placement into a conditioning chamber (BRS/LVE, Laurel, MD, USA; W $30.5 \mathrm{~cm}$ x D $24.1 \mathrm{~cm} \times \mathrm{H} 26.7 \mathrm{~cm}$ ) that served as the conditioned stimulus (CS). The conditioning chambers were contained within closable sound and light attenuating chambers (W $50.8 \mathrm{~cm} \times \mathrm{D} 34.3 \mathrm{~cm} \times \mathrm{H} 36.8 \mathrm{~cm}$ ) with house fans, located in a room separate from the animal colony. The conditioning chambers contained a standard footshock metal bar floor, two clear 
plastic front and black walls, a clear plastic ceiling, and two metal side walls. Below the bar floor, a floor tray containing cedar bedding was inserted to enhance the distinction of the conditioning environment from the home cage. In between animals, chambers were thoroughly cleaned using Roccal-D Plus disinfectant (Zoetis, Kalamazoo, MI).

Prior work in our laboratory has shown that unmanipulated animals, saline conditioned animals, or animals that received the CS and US in an unpaired manner do not demonstrate context-induced immunosuppression. This indicates that immunosuppression is specifically due to re-exposure to a heroin-paired CS and not ancillary effects of conditioning, receiving heroin, or injections in general (Lysle and Ijames, 2002).

Tissue Collection. Immediately after the 60-min test session (or home cage exposure for controls), rats were injected with LPS. Rats were sacrificed and tissue was collected 6 hours after LPS injection. The spleen was analyzed because immunohistochemical localization of iNOS in rats exposed to LPS shows the presence of the iNOS enzyme in a number of immune cells found in the spleen, including macrophages, lymphocytes, and neutrophils (Bandaletova et al., 1993). Following sacrifice, spleen was dissected out and cut into approximately $100 \mathrm{mg}$ sized pieces for RT-qPCR and ELISA. Tissue was placed in cOmplete Protease Inhibitor Cocktail (Roche Diagnostics, Indianapolis, IN) and stored at $-80^{\circ} \mathrm{C}$.

RNA Extraction \& RT-qPCR. To determine iNOS mRNA expression, reverse transcription quantitative real-time PCR (RT-qPCR) was performed on spleen tissue samples. Collected tissue was processed by the UNC Animal Clinical Chemistry and Gene Expression Laboratories according to previous protocols (Kim et al., 2002). Briefly, tissue was homogenized in RNA lysis buffer (PE Biosystems, Foster City, CA) with $\mathrm{Ca}_{2+}$ and $\mathrm{Mg}_{2-}$ free $\mathrm{PB}$ using a Fast Prep 120 mixer (QBIOgene, Vista, CA). RNA was purified using an automated nucleic-acid workstation (ABI Prism 6700, PE Biosystems) according to the manufacturer's protocol. The 
amount of RNA used in the RT-qPCR reaction (one-step) was equalized between samples. RTqPCR reactions were performed in a sequence detector (ABI Prism 7700, PE Biosystems) in a total volume of $30 \mu \mathrm{L}$ (10 $\mu \mathrm{L}$ RNA, $20 \mu \mathrm{L}$ reaction cocktail). Each RT-qPCR amplification was performed in duplicate under the following reaction conditions: $30 \mathrm{~min}$ at $48^{\circ} \mathrm{C}$ for the RT reaction, $10 \mathrm{~min}$ at $94^{\circ} \mathrm{C}$, and then 40 cycles of $15 \mathrm{~s}$ at $94^{\circ} \mathrm{C}$ and $1 \mathrm{~min}$ at $60^{\circ} \mathrm{C}$. Raw results were normalized to reference gene $18 \mathrm{~S}$ to control for small variations in the amount of starting cDNA template. The stability of $18 \mathrm{~S}$ as a reference gene was verified using a $2 \times 2$ ANOVA to demonstrate that there were no significant group differences in $18 \mathrm{~S}$ expression. Normalized values were then calibrated against either a global normalized average Ct value (Experiment 1) or a control group normalized average Ct (Experiment 2) for the gene of interest. For graphical representation, delta delta Ct values were linearly transformed. The nucleotide sequences of the qPCR primers and fluorogenic probes used for iNOS and 18S were as follows - iNOS forward: 5’-AGCGGCTCCATGACTCTCA-3', reverse: 5'-TGCCTGCACCCAAACACCAA-3', probe: 5'-FTCATGCGGCCTCCTTTGAGCCCTCQ-3'; 18S forward: AGAAACGGCTACCACATCCA-3', reverse: 5'-CTCGAAAGAGTCCTGTATTGT-3', probe: 5'-FAGGCAGCAGGCGCGCAAATTACQ-3' [F = 5'- Fluorescein (FAM); Q = Quencher (TAMRA)].

Protein Extraction/Quantification \& iNOS ELISA. Spleen tissue was homogenized on ice in sterile Dounce grinders. Protein was extracted from homogenized samples using cycles of freeze-thaw lysis, centrifugation, and collection of the supernatant. Total protein was quantified by Bradford Assay. Briefly, $10 \mu \mathrm{L}$ of 1:200 diluted protein, in triplicate, was incubated with 200 $\mu \mathrm{L}$ diluted and filtered Bradford Assay Dye (Bio-Rad Laboratories Inc., Hercules, CA, Catalog No. 500-0006) for $10 \mathrm{~min}$. The absorbance of each sample triplicate was measured in a spectrophotometer (Epoch ${ }^{\mathrm{TM}}$, BioTek Instruments Inc., Winooski, VT) at 595 nm, averaged, and 
compared to a concurrently run BSA standard curve to determine $\mu \mathrm{g} / \mu \mathrm{L}$ concentration. Splenic iNOS protein was quantified using a rat iNOS sandwich ELISA kit (LifeSpan BioSciences, Inc., Seattle, WA, Catalog No. LS-F4109). The user manual supplied with the kit was followed with the following parameters: $200 \mu \mathrm{g}$ of total protein per sample was loaded in duplicate, plates were gently agitated at 45-55 rpm, and color was allowed to develop for 20-25 min. The ELISA plate was washed with an automatic plate washer (EL 403, BioTek Instruments Inc., Winooski, VT) as recommended by the kit manual. Each plate was read in a spectrophotometer at $450 \mathrm{~nm}$ and compared to a concurrently run standard curve to determine pg iNOS protein per $200 \mu \mathrm{g}$ of total protein.

Nitrate/Nitrite Assay. The nitrate/nitrite concentration in plasma samples was assessed using the Greiss reagent assay as described previously (Szczytkowski and Lysle, 2007). Briefly, $12 \mu \mathrm{L}$ of plasma diluted in $38 \mu \mathrm{L}$ of $\mathrm{dH}_{2} \mathrm{O}$ was incubated in the dark for 90 min with $10 \mu \mathrm{L}$ of nitrate reductase $(1.0 \mathrm{U} / \mathrm{mL}), 20 \mu \mathrm{L}$ of $0.31 \mathrm{M}$ phosphate buffer $(\mathrm{pH} 7.5), 10 \mu \mathrm{L}$ of $0.86 \mathrm{mM}$ beta-nicotinamide adenine dinucleotide phosphate reduced tetrasodium salt (NADPH, SigmaAldrich Inc., Milwaukee, WI), and $10 \mu \mathrm{L}$ of $0.11 \mathrm{mM}$ flavin adenine dinucleotide in individual wells of a 96-well plate. Then, $200 \mathrm{~mL}$ of Greiss reagent, consisting of a 1:1 (v/v) solution 1\% sulfanilamide in $5.0 \%$ phosphoric acid and $0.1 \%$ N-(1-Naphthyl)ethylenediamine dihydrochloride (Kodak) in distilled water, was added to the samples. The color developed for 10 min at room temperature, after which, absorbance at $550 \mathrm{~nm}$ was determined using a spectrophotometer. All reactions were carried out in triplicate. The total micromolar concentration of nitrite was determined for each sample based on a concurrently produced standard curve. Recovery of nitrate is greater than $95 \%$ using this assay.

Histology. To confirm proper cannula placement, Alcian blue dye was infused via the cannulae following euthanasia. For Experiment 1, brains were extracted and immediately flash 
frozen in a low temperature freezing bath (Histobath NesLab, Portsmouth, NH; Shandon Lipshaw, Pittsburgh, PA) with freezing-cold isopentane, wrapped in aluminum foil, and stored at $-80^{\circ} \mathrm{C}$. For Experiment 2, brains were extracted and post-fixed at $4{ }^{\circ} \mathrm{C}$ for 5 days in $4 \%$ paraformaldehyde. Following fixation, the brains were transferred to $30 \%$ sucrose solution for three days for cryoprotection. Brains were then frozen in a low temperature freezing bath (Histobath NesLab, Portsmouth, NH; Shandon Lipshaw, Pittsburgh, PA) with freezing-cold isopentane, wrapped in aluminum foil, and stored at $-80^{\circ} \mathrm{C}$. For both experiments, $40 \mu \mathrm{m}$ coronal sections were collected using a freezing microtome (Leica CM 3050 S, Leica-Microsystems, Germany) and allowed to dry on the slide for $30 \mathrm{~min}$ at room temperature before analysis. Cannula tracts were identified under a light microscope and the most ventral point of each tract was documented on rat brain atlas figures. Subjects with incorrect placement of cannula were removed from all analyses. Sections were stained with thionin and coverslipped for long-term storage.

Statistical Analysis. A 2x2 analysis of variance (ANOVA) was performed on data sets using SPSS Statistics (IBM, Armonk, NY), after verifying that the underlying assumptions of the test were met. Homogeneity of variance was tested using Levene's Test and normality using Shapiro-Wilk Test. For all tests, the significance level was set at 0.05. Tukey's Honestly Significant Difference (HSD) post-hoc test was then used to detect either differences between CS-exposed and corresponding home cage control groups (Experiment 1) or differences between heroin-injected vs. saline-injected groups and the effect of pre-treatment with IL-1RA vs. saline within heroin-injected groups (Experiment 2). For RT-qPCR, statistics were run on delta delta Ct values and not the linear transform because the former demonstrated normality. 


\section{Experiment Specific Procedures}

\section{Experiment 1: IL-1RA Antagonism During Acquisition of Heroin Conditioned}

Immunosuppression. For Experiment 1, animals $(\mathrm{N}=31)$ were repeatedly microinjected with IL-1RA into the DH at two time points relative to conditioning. One group (IL-1RA With Cond; $\mathrm{n}=16)$ received IL-1RA 30 minutes prior to receiving heroin and being placed into the conditioning chamber to test whether DH IL-1 signaling during conditioning is required for acquisition of heroin conditioned immunosuppression. Another group (IL-1RA 24 h After Cond; $\mathrm{n}=15$ ) received IL-1RA 24 hours after conditioning, on the days in between conditioning sessions (non-conditioning days), to test whether IL-1 signaling is specifically required during conditioning sessions for acquisition. For both groups, infusions were given on both conditioning and non-conditioning days and vehicle infusions were given at times when animals were not administered IL-1RA (Figure 1). This design ensured that all animals received injections before

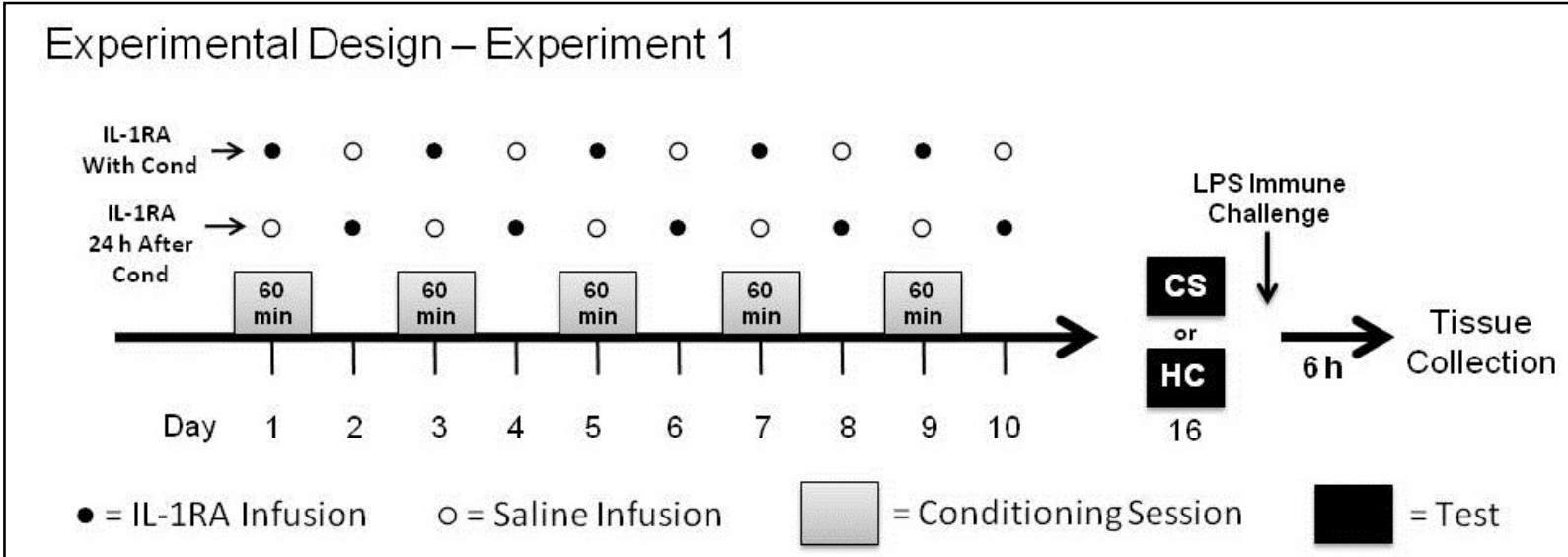

Figure 1. Experimental Design of Experiment 1.Following a surgery recovery period, rats were conditioned to associate a heroin injection with a distinct context. Rats in one group received an infusion of IL-1 receptor antagonist (IL-1RA) into the dorsal hippocampus (DH) 30 min before each of the five conditioning sessions (IL-1RA With Cond). Rats in another group received an IL-1RA infusion into the DH $24 \mathrm{~h}$ after the previous conditioning session, on non-conditioning days (IL-1RA $24 \mathrm{~h}$ After Cond). Number of injections and injection manipulations were balanced between each group using saline infusions. Six days after the last infusion, half of the animals from each group were either re-exposed to the heroin-paired context (CS) to test for conditioned immunosuppression or remained in the home-cage for an equivalent period of time (HC). Immediately following, all animals were given a single injection of LPS and were sacrificed 6 hours later. 
conditioning and that all animals received the same total number of IL-1RA infusions. This meant that differences between groups would not reflect ancillary effects of infusion timing relative to conditioning nor possible non-specific compensatory effects from receiving multiple IL-1RA injections. IL-1RA has a short half-life when injected systemically (21-108 minutes) (Granowitz et al., 1992). Unfortunately there is no data confirming the timeline of IL-1RA clearance from brain tissue. However, studies investigating effects of intracerebroventricular or hippocampal infusion of IL-1RA have shown that IL-1RA effects may last on the order of hours (Schmid et al., 2009; Schneider et al., 1998). This evidence suggests that separating IL-1RA treatment regimens by a full day, as in the current study, will likely limit temporal overlap of IL1RA action between groups.

Six days after the last infusion (seven from the last conditioning session), half of the rats from each group were tested for expression of conditioned immunosuppression by being reexposed to the conditioning chamber (CS) for a single 60-min session, while the other half were not re-exposed and instead remained in their home cages (HC) for 60 min. Thus, conditioning in the latter group of home-cage controls was not evoked and this group was used for baseline comparison within each treatment regimen. Immediately thereafter, all rats received a single subcutaneous injection of LPS to induce in vivo production of nitric oxide. Rats were sacrificed 6 hours after LPS injection by cervical dislocation and a sample of spleen and blood were obtained for the analysis of iNOS mRNA, iNOS protein, and nitrate/nitrite.

\section{Experiment 2: IL-1RA Antagonism During Heroin Unconditioned}

Immunosuppression. For Experiment 2, animals $(\mathrm{N}=24)$ received a DH infusion of either IL1RA or vehicle 30 min before a single subcutaneous heroin or saline injection (Figure 2). In order to mirror the time point of Experiment 1, animals were returned to their home cage for an hour, the length of Experiment 1 conditioning sessions, and were then injected a single time 
subcutaneously with LPS to induce in vivo production of nitric oxide. Six hours after LPS injection, rats were sacrificed by cervical dislocation and a sample of spleen and blood were obtained for the analysis of iNOS mRNA, iNOS protein, and nitrate/nitrite.

\section{Experimental Design - Experiment 2}

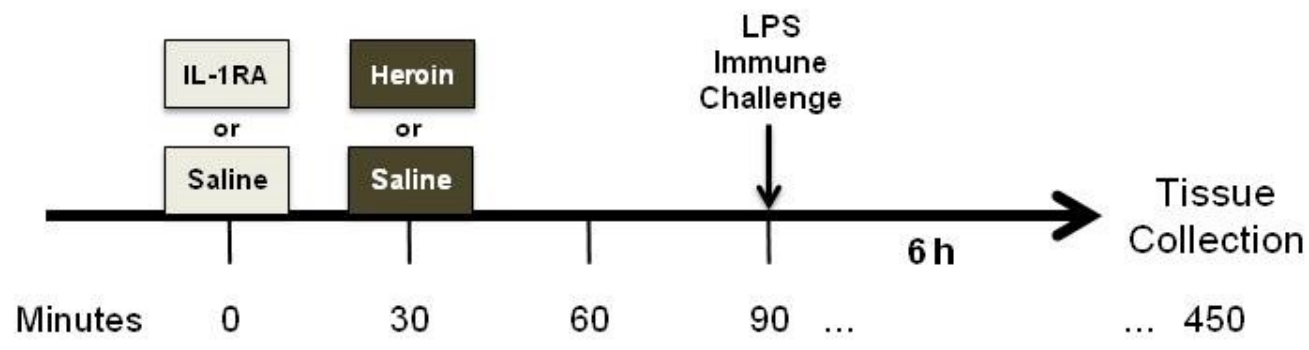

Figure 2. Experimental Design of Experiment 2. Following a surgery recovery period, rats received an infusion of IL-1 receptor antagonist (IL-1RA) or saline (Sal) into the dorsal hippocampus (DH) $30 \mathrm{~min}$ before a single subcutaneous injection of saline (Sal) or heroin (Her). One hour later, all animals were given a single injection of LPS and were sacrificed 6 hours later.

\section{Results}

Experiment 1 investigated the effects of DH IL-1 signaling blockade on the acquisition of heroin conditioned immunosuppression by injecting IL-1RA into the DH either during each conditioning session or 24 hours after each conditioning session, on non-conditioning days. In the final analyses, group sizes were $\mathrm{n}=8$ for IL-1RA With Cond - HC, IL-1RA With Cond - CS, and IL-1RA 24 h After Cond - CS groups. For the IL-1RA 24 h After Cond - HC group, $n=7$ for nitrate/nitrate and iNOS protein analyses and $n=6$ for iNOS mRNA analyses. One subject was removed from iNOS mRNA analysis due to outlying housekeeping data that signified a problem with RNA extraction/cDNA synthesis.

A 2x2 ANOVA revealed significant differences between groups for splenic iNOS mRNA $\left(\mathrm{F}_{(3,26)}=13.857, p<0.001\right.$, Figure 3A). There were significant main effects of drug timing $\left(\mathrm{F}_{(1,26)}=11.387, p<0.01\right)$ and exposure treatment $\left(\mathrm{F}_{(1,26)}=23.836, p<0.001\right)$ on iNOS mRNA. 
Post-hoc analysis, using Tukey’s HSD, revealed that iNOS mRNA was statistically significantly reduced in animals that were re-exposed to the CS and received IL-1RA $24 \mathrm{~h}$ after conditioning (IL-1RA 24 h After Cond - CS), compared to the corresponding home cage control group that

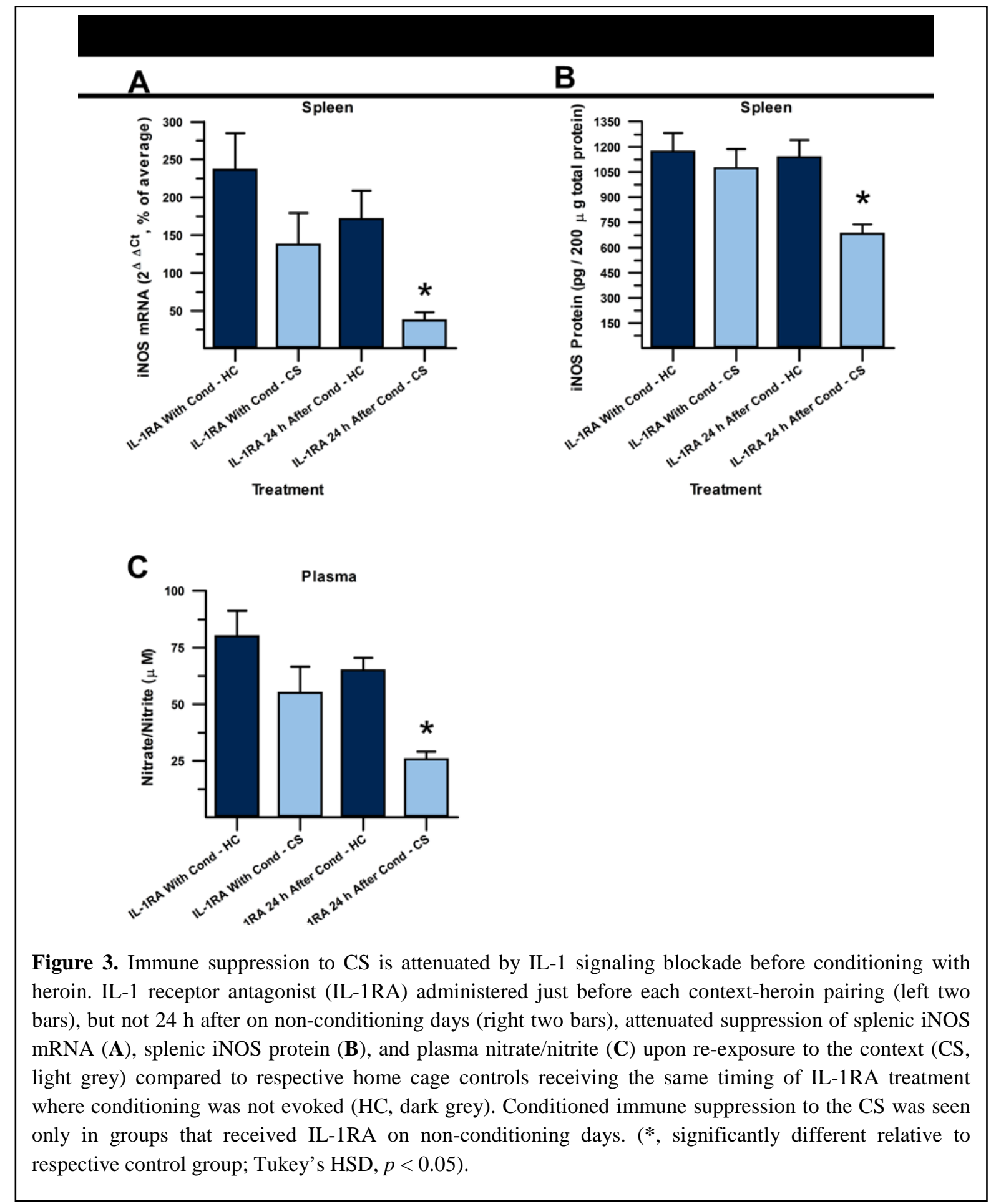


was not re-exposed but received the same treatment regimen (IL-1RA 24 h After Cond - HC, $p<$ 0.001). No statistically significant suppression of iNOS mRNA was seen in animals re-exposed to the CS that received IL-1RA treatment just before each conditioning session (IL-1RA With Cond - CS), compared to the corresponding home cage control group that was not re-exposed (IL-1RA With Cond - HC, $p>0.17$ ), indicating that DH IL-1RA blocked the acquisition of heroin conditioned suppression of iNOS mRNA when administered just before, but not $24 \mathrm{~h}$ after, conditioning sessions.

A 2x2 ANOVA revealed significant differences between groups for splenic iNOS protein as well $\left(\mathrm{F}_{(3,27)}=6.073, p<0.01\right.$, Figure 3B). There were significant main effects of drug timing $\left(\mathrm{F}_{(1,27)}=5.244, p<0.04\right)$ and exposure treatment $\left(\mathrm{F}_{(1,27)}=8.83, p<0.01\right)$ on iNOS protein. Posthoc analysis, using Tukey's HSD, revealed that, like with iNOS mRNA, iNOS protein was statistically significantly reduced in animals that received DH IL-1RA $24 \mathrm{~h}$ after conditioning, on non-conditioning days, and were re-exposed to the CS (IL-1RA $24 \mathrm{~h}$ After Cond - CS) compared to the corresponding home cage control group that was not re-exposed but received the same treatment regimen (IL-1RA 24 h After Cond - HC, $p<0.02$ ). No statistically significant suppression of iNOS protein was seen in animals that received IL-1RA treatment just before each conditioning session (IL-1RA With Cond - CS) compared to the corresponding home cage control group that was not re-exposed (IL-1RA With Cond $-\mathrm{HC}, p>0.87$ ). These results demonstrate that IL-1RA administration into the DH during conditioning, but not $24 \mathrm{~h}$ later, disrupts the acquisition of heroin conditioned suppression of iNOS protein.

A 2x2 ANOVA revealed significant differences between groups for plasma nitrate/nitrite as well $\left(\mathrm{F}_{(3,27)}=7.518, p<0.01\right.$, Figure $\left.3 \mathrm{C}\right)$. There were significant main effects of drug timing $\left(\mathrm{F}_{(1,27)}=6.810, p<0.02\right)$ and exposure treatment $\left(\mathrm{F}_{(1,27)}=14.387, p<0.01\right)$ on plasma nitrate/nitrite. Post-hoc analysis, using Tukey’s HSD, revealed that nitrate/nitrite was statistically 
significantly reduced in animals that received IL-1RA $24 \mathrm{~h}$ later on non-conditioning days when re-exposed to the CS (IL-1RA $24 \mathrm{~h}$ After Cond - CS) in comparison to the corresponding home cage control group that was not re-exposed (IL-1RA 24 h After Cond - HC, $p<0.02$ ). No statistically significant suppression of nitrate/nitrite upon re-exposure to the CS was seen in animals that received IL-1RA treatment just before each conditioning session (IL-1RA With Cond - CS) compared to the corresponding home cage control group that was not re-exposed (IL-1RA With Cond - HC, $p>0.17$ ).

Thus, we observed significant attenuation of heroin conditioned immunosuppression when IL-1RA was infused into the DH just before, but not $24 \mathrm{~h}$ after, each conditioning session in both iNOS mRNA and protein and in plasma nitrate/nitrite. This indicates that IL-1 signaling blockade in the DH during conditioning sessions blocks acquisition of heroin conditioned immunosuppression.

Experiment 2 investigated the effects of DH IL-1 signaling blockade on heroin unconditioned immunosuppression. In the final analyses, group sizes were $n=6$ for the Sal/Sal group, $\mathrm{n}=7$ for Sal/Her and IL-1RA/Sal groups, and $\mathrm{n}=4$ for the IL-1RA/Sal group. Three subjects were removed from analysis due to incorrect cannula placement.

A 2x2 ANOVA revealed a significant difference between treatment groups (iNOS mRNA: $\mathrm{F}_{(3,20)}=9.604, p<0.001$, Figure 4A; iNOS protein: $\mathrm{F}_{(3,20)}=16.007, p<0.001$, Figure 4B; nitrate/nitrite: $\mathrm{F}_{(3,20)}=13.934, p<0.001$, Figure 4C). There was a significant main effect of heroin treatment for iNOS mRNA $\left(\mathrm{F}_{(1,20)}=26.050, p<0.001\right)$, iNOS protein $\left(\mathrm{F}_{(1,20)}=46.741, p\right.$ $<0.001)$, and plasma nitrate/nitrite $\left(\mathrm{F}_{(1,20)}=40.728, p<0.001\right)$. There was no main effect of IL1RA treatment for iNOS mRNA, iNOS protein, or nitrate/nitrite ( $p>0.4$ for all measures). Posthoc analysis, using Tukey's HSD, revealed that heroin-injected groups showed significantly decreased immune activation compared to saline-injected control groups (iNOS mRNA: $p<$ 
0.05; iNOS protein: $p<0.006$; nitrate/nitrite: $p<0.01$ ), but there was no effect of IL-1RA treatment on heroin suppression of these measures to immune challenge (iNOS mRNA: $p>0.38$;

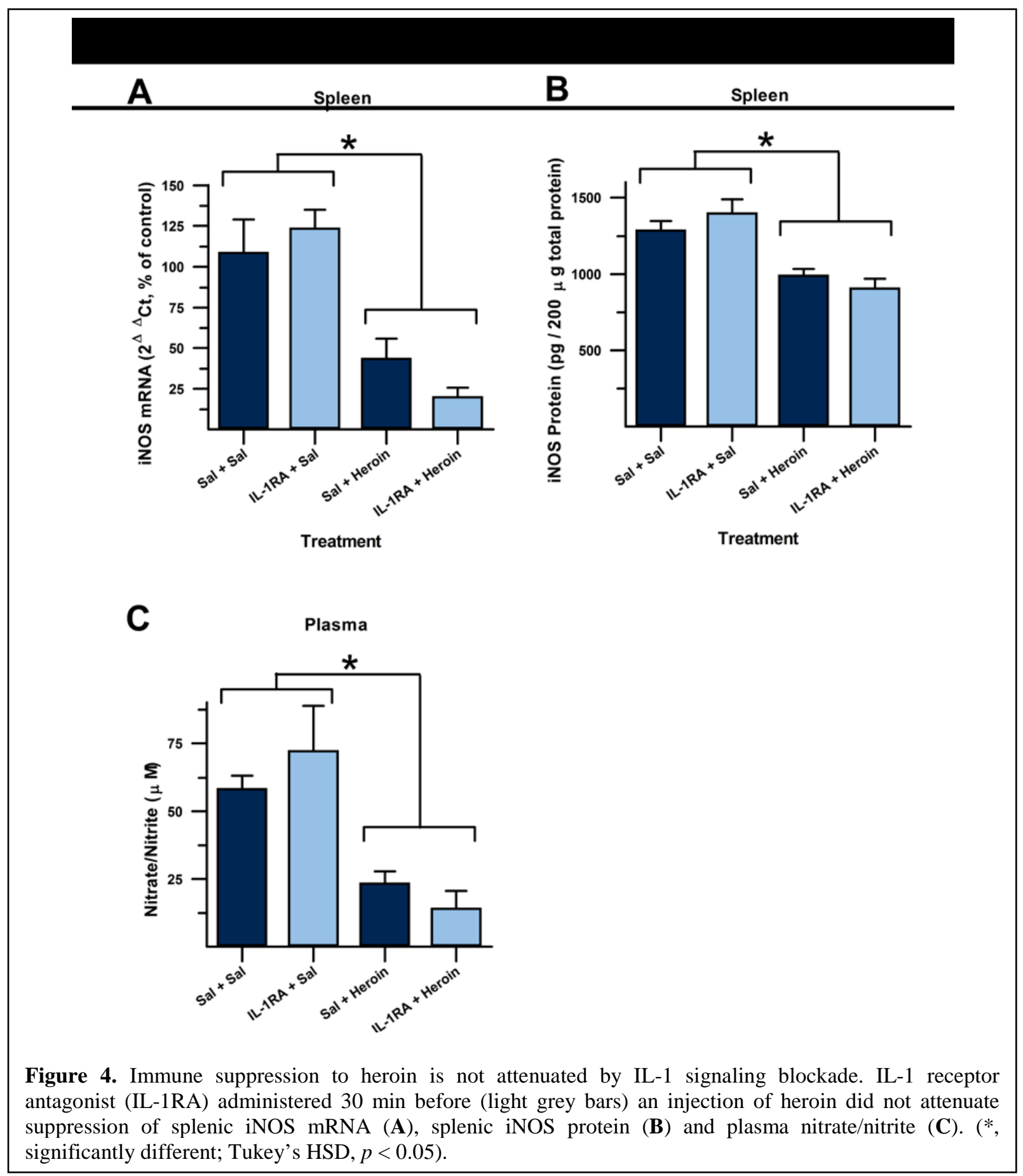

iNOS protein: $p>0.68$; nitrate/nitrite: $p>0.74$ ). This indicates that IL-1RA in the DH does not block unconditioned immunosuppression by a single heroin injection. It is possible, however, 
that over repeated treatments of heroin and IL-1RA, as in the dosing regimen used in Experiment 1, that effects of IL-1RA on heroin immunosuppression would begin to arise.

\section{Discussion}

Heroin-paired contexts gain the ability to suppress the immune system, like heroin itself, through conditioning. This effect could contribute to the increased risk of infection seen in heroin users. Evidence suggests that the cytokine interleukin-1 $(\mathrm{IL}-1 \beta$ ) is required at physiological levels to support learning and memory. We demonstrate here that preventing IL-1 signaling centrally in the dorsal hippocampus (DH) during each conditioning session in the acquisition phase, a time when heroin and a context can become associated, prevents the heroinpaired context from suppressing the immune system during a subsequent expression test. This effect was not seen if IL-1 signaling was blocked in the DH between conditioning sessions on non-conditioning days. Subsequently, we tested whether blocking IL-1 signaling in the DH would attenuate heroin immunosuppression in order to address whether the effect seen in acquisition is due to the interruption of learning and memory or, alternatively, due to blocking the immune effects of heroin. Our results suggest that blocking IL-1 signaling in the DH does not interfere with acquisition of heroin conditioned immunosuppression by attenuating the immunosuppressive effects of heroin, but rather that IL-1 signaling may be specifically involved in associative memory formation. However, this conclusion must be tempered with the fact that this experiment used a single injection of heroin and a single infusion of IL-1RA. It is unclear whether effects would be seen with multiple heroin and/or IL-1RA injections, as used in Experiment 1 . This possibility will need to be investigated.

These results suggest that hippocampal IL-1 signaling is required for the acquisition of heroin conditioned immunosuppression, which is in agreement with previous reports demonstrating the importance of IL-1 signaling in other hippocampal-dependent forms of 
memory. However, results from the current study contrast with those of other studies investigating conditioned immunosuppression. In particular, Pacheco-López and colleagues (2007) showed that intracerebroventricular infusion of IL-1RA had no effect on the acquisition of taste-LPS associative memory (Pacheco-Lopez et al., 2007). We propose that this incongruence may be due to differences in the neural circuitry involved in the acquisition and expression of conditioned taste-immune vs. conditioned opiate-immune effects. It is unclear whether conditioned taste effects require the hippocampus in paradigms not employing a contextual component (Molero-Chamizo and Moron, 2015). In addition, prior studies demonstrated that the amygdala was important for the expression of heroin conditioned immunosuppression (Szczytkowski et al., 2011; Szczytkowski and Lysle, 2008, 2010). Immune conditioning studies using cyclosporine A paired with a tastant, in contrast, have shown that this area was only required during acquisition of conditioned immunosuppression and not during expression (Pacheco-Lopez et al., 2005). These differences may be due to the use of different unconditioned and conditioned stimuli between taste and opiate conditioned immune effects, differential reliance on contextual memory, or differences in experimental design (e.g. targeting the basolateral aspect of the amygdala specifically versus the whole amygdalar complex). It was also demonstrated that the insular cortex and ventromedial hypothalamus were required throughout taste conditioned immmunosuppression or only during expression, respectively (Pacheco-Lopez et al., 2005), but it is unknown whether these regions are also required for contextual immune conditioning using heroin. Future studies should investigate these potential valuable distinctions.

Though it might be argued that repeated suppression of IL-1 signaling could disrupt heroin conditioned immunosuppression through non-specific compensatory mechanisms, the disruption of acquisition of this learned effect only when IL-1RA was administered into the DH 
before conditioning and not on days when conditioning did not take place, argues against this notion.

From the current results, it is still unclear whether hippocampal IL-1 signaling increases during the acquisition phase of heroin conditioned immunosuppression, or whether only basal levels are required for heroin context-immune associations to form. There is a plethora of experimental evidence that opioids can increase the activation of microglia and astrocytes through either glial $\mu$-opioid receptor or toll-like receptor 4 (TLR4) activation, leading to the release of proinflammatory cytokines, including IL-1 $\beta$ (Coller and Hutchinson, 2012; Hutchinson et al., 2011; Motaghinejad et al., 2015; Wang et al., 2012). However, most of these studies were conducted in the spinal cord or under longer-term treatment with opioids than what was used in the present studies. Chronic morphine has been shown to elevate astrocyte activation in the hippocampus (Song and Zhao, 2001), but again, it is unclear whether this would occur following five doses of heroin or whether this would lead to increased release of IL-1 $\beta$. Stressinduced IL-1 $\beta$ expression was reduced in the dentate gyrus by morphine (Jones et al., 2015), indicating that opioids may have differential effects in different subregions of the hippocampus or that opioid action might depend on prior inflammatory states.

Neurons might also contribute to the release of IL- $1 \beta$ since both glia and neurons have been shown to release IL-1 $\beta$ in the brain (Goshen et al., 2007). TLR4 activation, being upstream of IL$1 \beta$ release from glia, might also lead to opioid-mediated release of cytokines from neurons. Additionally, if heroin activates microglia in our paradigm, this may lead to potentiated release of IL-1 $\beta$ from neurons. Microglial activation following brain injury has been shown to upregulate TLR4 expression on hippocampal neurons (Li et al., 2015). Interestingly, this neuronal change in TLR4 expression was coupled with increased hippocampal excitability, especially in the dentate gyrus, and was increased or decreased by TLR4 agonists or antagonists, 
respectively. While this effect was not linked to the release of IL-1 $\beta$ directly, there is additional evidence indicating that a functional consequence of IL-1 $\beta$ release in the hippocampus could be modulation of neuronal excitability. IL-1 $\beta$ has been shown to cause changes in NMDA and AMPA receptor dynamics in the hippocampus, inhibit voltage dependent calcium channels in CA1, cause permanent inhibition of GABAergic signaling in dentate gyrus and CA3 neurons, and yet increase GABAergic signaling in CA1 [see (Schafers and Sorkin, 2008; Vezzani and Viviani, 2015)].

Also of note is the possibility of $\mathrm{CB}_{1}$-dependent regulation of opioid immune signaling. Heroin has been shown to produce $\mathrm{CB}_{1}$ signaling adaptations in the hippocampus following acquisition of self-administration (Fattore et al., 2007), indicating that opioids may modulate tonic expression of endocannabinoid signaling the hippocampus. There is evidence that basal expression of IL-1 $\beta$ in the hippocampus requires cannabinoid receptor, CB $_{1}$ (Csolle and Sperlagh, 2011) therefore, there are multiple ways that opiates might modulate expression of IL$1 \beta$ in the hippocampus so that IL- $1 \beta$ can contribute to heroin learning. The functional consequence of this IL-1 $\beta$ regulation may be subregion specific changes in neuronal excitability in the hippocampus. Future experiments should aim to explore IL-1 $\beta$ expression, glial activation, and the neuromodulatory functions of IL- $1 \beta$ in each of the subregions of the hippocampus within our heroin conditioning regimen.

It must be noted that our manipulation used the IL-1R1 endogenous receptor antagonist, IL-1RA. This receptor also binds to IL-1 alpha (IL-1 $\alpha$ ) and mediates its action, so the specificity of IL-1 $\beta$ in mediating the effects seen cannot be concluded definitively. Previous studies have shown that IL-1 $\beta$ signaling is required for the expression of heroin conditioned immunosuppression to a context through knockdown of IL-1 $\beta$ expression using IL-1 $\beta$ siRNA (Szczytkowski et al., 2013). For the current experiment, IL-1 $\beta$ siRNA was not temporally 
specific enough to target processes only during or shortly after each conditioning session. It has been shown in our experience to knockdown expression in vivo for at least 48 hours (Szczytkowski et al., 2013), and it has the potential to knockdown gene expression for up to four days (Dr. H. Y. Eminy Lee, Personal communication, 2010). IL-1RA, on the other hand, could have a much more acute effect, which is why it was used in the present study. Our results seem to confirm that the effects of administering IL-1RA 24 hours apart were distinguishable.

To our knowledge, despite the fact that a preponderance of evidence suggests that opioid use can suppress the immune system in animal models, primates, and humans along with concerning evidence that this extends to clinical use, there has been no investigation as to the prevalence of opioid conditioned immunosuppression in therapeutic opioid use (Al-Hashimi et al., 2013; Brown et al., 2012; Sacerdote, 2006; Sacerdote et al., 2012; Santamaria et al., 2010; Vallejo et al., 2004; Wu et al., 2015). Conditioned immunosuppression using other immunosuppressive drugs has been demonstrated in humans in the placebo literature (Albring et al., 2014; Albring et al., 2012; Goebel et al., 2002), so it is reasonable to hypothesize that opioid immune effects would be able to be conditioned in humans as well. This possibility should be explored in the future as it has the potential to greatly impact the clinical use of opioids in pain and cancer management. The current results suggest that therapeutic inhibition of IL-1 during the acquisition phase of associations between the immune system with opioids may help prevent usually benign stimuli from suppressing the immune system and may block increased infection risk. While more difficult to make use of this treatment in the case of heroin users, IL-1 inhibition could potentially alleviate immunosuppressive consequences of clinical opioid use. Further studies should be conducted to relate the current results to clinical application. The direct impact of hippocampal IL-1 blockade on pathogen resistance outcomes should be empirically tested. This study provides valuable insight into the neural mechanisms that contribute to heroin 
conditioned immunosuppression and characterizes IL-1 effects on an important measure of conditioned immunity.

\section{Acknowledgement}

This research was supported by National Institute on Drug Abuse grants DA034721 and DA007244. C. L. Lebonville was supported by Chase Dashiell \& Crane Graduate Student Award and National Science Foundation Graduate Research Fellowship DGE-1144081. 


\section{REFERENCES}

Ader, R., 1974. Behaviorally Conditioned Immunosuppression. Psychosom Med 36, 183-184.

Ader, R., Cohen, N., 1975. Behaviorally Conditioned Immunosuppression. Psychosom Med 37, 333-340.

Al-Hashimi, M., Scott, S.W., Thompson, J.P., Lambert, D.G., 2013. Opioids and immune modulation: more questions than answers. British journal of anaesthesia 111, 80-88.

Albring, A., Wendt, L., Benson, S., Nissen, S., Yavuz, Z., Engler, H., Witzke, O., Schedlowski, M., 2014. Preserving learned immunosuppressive placebo response: perspectives for clinical application. Clin Pharmacol Ther 96, 247-255.

Albring, A., Wendt, L., Benson, S., Witzke, O., Kribben, A., Engler, H., Schedlowski, M., 2012. Placebo effects on the immune response in humans: the role of learning and expectation. PloS one 7 , e49477.

Avital, A., Goshen, I., Kamsler, A., Segal, M., Iverfeldt, K., Richter-Levin, G., Yirmiya, R., 2003. Impaired interleukin-1 signaling is associated with deficits in hippocampal memory processes and neural plasticity. Hippocampus 13, 826-834.

Bandaletova, T., Brouet, I., Bartsch, H., Sugimura, T., Esumi, H., Ohshima, H., 1993. Immunohistochemical localization of an inducible form of nitric oxide synthase in various organs of rats treated with Propionibacterium acnes and lipopolysaccharide. APMIS : acta pathologica, microbiologica, et immunologica Scandinavica 101, 330-336.

Ben Menachem-Zidon, O., Avital, A., Ben-Menahem, Y., Goshen, I., Kreisel, T., Shmueli, E.M., Segal, M., Ben Hur, T., Yirmiya, R., 2011. Astrocytes support hippocampal-dependent memory and long-term potentiation via interleukin-1 signaling. Brain, behavior, and immunity 25,1008 1016 .

Bogdan, C., 2001. Nitric oxide and the immune response. Nature immunology 2, 907-916.

Brown, J.N., Ortiz, G.M., Angel, T.E., Jacobs, J.M., Gritsenko, M., Chan, E.Y., Purdy, D.E., Murnane, R.D., Larsen, K., Palermo, R.E., Shukla, A.K., Clauss, T.R., Katze, M.G., McCune, J.M., Smith, R.D., 2012. Morphine produces immunosuppressive effects in nonhuman primates at the proteomic and cellular levels. Mol Cell Proteomics 11, 605-618.

Caroff, M., Karibian, D., Cavaillon, J.M., Haeffner-Cavaillon, N., 2002. Structural and functional analyses of bacterial lipopolysaccharides. Microbes and infection / Institut Pasteur 4, 915-926.

Coller, J.K., Hutchinson, M.R., 2012. Implications of central immune signaling caused by drugs of abuse: Mechanisms, mediators and new therapeutic approaches for prediction and treatment of drug dependence. Pharmacol Therapeut 134, 219-245. 
Coussons-Read, M.E., Dykstra, L.A., Lysle, D.T., 1994a. Pavlovian conditioning of morphineinduced alterations of immune status: evidence for opioid receptor involvement. Journal of neuroimmunology 55, 135-142.

Coussons-Read, M.E., Dykstra, L.A., Lysle, D.T., 1994b. Pavlovian conditioning of morphineinduced alterations of immune status: evidence for peripheral beta-adrenergic receptor involvement. Brain, behavior, and immunity 8, 204-217.

Coussons, M.E., Dykstra, L.A., Lysle, D.T., 1992. Pavlovian conditioning of morphine-induced alterations of immune status. Journal of neuroimmunology 39, 219-230.

Csolle, C., Sperlagh, B., 2011. Endocannabinergic modulation of interleukin-1beta in mouse hippocampus under basal conditions and after in vivo systemic lipopolysaccharide stimulation. Neuroimmunomodulation 18, 226-231.

Exton, M.S., Herklotz, J., Westermann, J., Schedlowski, M., 2001. Conditioning in the rat: an in vivo model to investigate the molecular mechanisms and clinical implications of brain-immune communication. Immunological reviews 184, 226-235.

Exton, M.S., von Horsten, S., Schult, M., Voge, J., Strubel, T., Donath, S., Steinmuller, C., Seeliger, H., Nagel, E., Westermann, J., Schedlowski, M., 1998a. Behaviorally conditioned immunosuppression using cyclosporine A: central nervous system reduces IL-2 production via splenic innervation. Journal of neuroimmunology 88, 182-191.

Exton, M.S., Von Horsten, S., Voge, J., Westermann, J., Schult, M., Nagel, E., Schedlowski, M., 1998b. Conditioned taste aversion produced by cyclosporine A: concomitant reduction in lymphoid organ weight and splenocyte proliferation. Physiol Behav 63, 241-247.

Fattore, L., Vigano, D., Fadda, P., Rubino, T., Fratta, W., Parolaro, D., 2007. Bidirectional regulation of mu-opioid and $\mathrm{CB} 1$-cannabinoid receptor in rats self-administering heroin or WIN 55,212-2. European Journal of Neuroscience 25, 2191-2200.

Fecho, K., Maslonek, K.A., Dykstra, L.A., Lysle, D.T., 1996. Assessment of the involvement of central nervous system and peripheral opioid receptors in the immunomodulatory effects of acute morphine treatment in rats. Journal of Pharmacology and Experimental Therapeutics 276, 626636.

Goebel, M.U., Trebst, A.E., Steiner, J., Xie, Y.F., Exton, M.S., Frede, S., Canbay, A.E., Michel, M.C., Heemann, U., Schedlowski, M., 2002. Behavioral conditioning of immunosuppression is possible in humans. Faseb J 16, 1869-1873.

Goshen, I., Kreisel, T., Ounallah-Saad, H., Renbaum, P., Zalzstein, Y., Ben-Hur, T., LevyLahad, E., Yirmiya, R., 2007. A dual role for interleukin-1 in hippocampal-dependent memory processes. Psychoneuroendocrino 32, 1106-1115.

Govitrapong, P., Suttitum, T., Kotchabhakdi, N., Uneklabh, T., 1998. Alterations of immune functions in heroin addicts and heroin withdrawal subjects. Journal of Pharmacology and Experimental Therapeutics 286, 883-889. 
Granowitz, E.V., Porat, R., Mier, J.W., Pribble, J.P., Stiles, D.M., Bloedow, D.C., Catalano, M.A., Wolff, S.M., Dinarello, C.A., 1992. Pharmacokinetics, safety and immunomodulatory effects of human recombinant interleukin-1 receptor antagonist in healthy humans. Cytokine 4, 353-360.

Griffin, W.S., Stanley, L.C., Ling, C., White, L., MacLeod, V., Perrot, L.J., White, C.L., 3rd, Araoz, C., 1989. Brain interleukin 1 and S-100 immunoreactivity are elevated in Down syndrome and Alzheimer disease. Proceedings of the National Academy of Sciences of the United States of America 86, 7611-7615.

Horsburgh, C.R., Anderson, J.R., Boyko, E.J., 1989. Increased Incidence of Infections in Intravenous Drug-Users. Infect Cont Hosp Ep 10, 211-215.

Hutchinson, M.R., Shavit, Y., Grace, P.M., Rice, K.C., Maier, S.F., Watkins, L.R., 2011. Exploring the Neuroimmunopharmacology of Opioids: An Integrative Review of Mechanisms of Central Immune Signaling and Their Implications for Opioid Analgesia. Pharmacological reviews $63,772-810$.

Jones, M.E., Lebonville, C.L., Barrus, D., Lysle, D.T., 2015. The Role of Brain Interleukin-1 in Stress-Enhanced Fear Learning. Neuropsychopharmacology : official publication of the American College of Neuropsychopharmacology 40, 1289-1296.

Kim, H.S., Lee, G., John, S.W., Maeda, N., Smithies, O., 2002. Molecular phenotyping for analyzing subtle genetic effects in mice: application to an angiotensinogen gene titration. Proceedings of the National Academy of Sciences of the United States of America 99, 46024607.

Kubera, M., Filip, M., Budziszewska, B., Basta-Kaim, A., Wydra, K., Leskiewicz, M., Regulska, M., Jaworska-Feil, L., Przegalinski, E., Machowska, A., Lason, W., 2008. Immunosuppression induced by a conditioned stimulus associated with cocaine self-administration. J Pharmacol Sci 107, 361-369.

Lewis, N.D., Asim, M., Barry, D.P., Singh, K., de Sablet, T., Boucher, J.L., Gobert, A.P., Chaturvedi, R., Wilson, K.T., 2010. Arginase II Restricts Host Defense to Helicobacter pylori by Attenuating Inducible Nitric Oxide Synthase Translation in Macrophages. Journal of Immunology 184, 2572-2582.

Li, Y., Korgaonkar, A.A., Swietek, B., Wang, J.F., Elgammal, F.S., Elkabes, S., Santhakumar, V., 2015. Toll-like receptor 4 enhancement of non-NMDA synaptic currents increases dentate excitability after brain injury. Neurobiology of disease 74, 240-253.

Louria, D.B., Hensle, T., Rose, J., 1967. The major medical complications of heroin addiction. Annals of internal medicine 67, 1-22.

Luecken, L.J., Lysle, D.T., 1992. Evidence for the involvement of beta-adrenergic receptors in conditioned immunomodulation. Journal of neuroimmunology 38, 209-219.

Lynch, M.A., 2015. Neuroinflammatory changes negatively impact on LTP: A focus on IL-1 beta. Brain research 1621, 197-204. 
Lysle, D.T., Cunnick, J.E., Fowler, H., Rabin, B.S., 1988. Pavlovian conditioning of shockinduced suppression of lymphocyte reactivity: acquisition, extinction, and preexposure effects. Life Sci 42, 2185-2194.

Lysle, D.T., Hoffman, K.E., Dykstra, L.A., 1996. Evidence for the involvement of the caudal region of the periaqueductal gray in a subset of morphine-induced alterations of immune status. The Journal of pharmacology and experimental therapeutics 277, 1533-1540.

Lysle, D.T., How, T., 2000. Heroin modulates the expression of inducible nitric oxide synthase. Immunopharmacology 46, 181-192.

Lysle, D.T., Ijames, S.G., 2002. Heroin-associated environmental stimuli modulate the expression of inducible nitric oxide synthase in the rat. Psychopharmacology 164, 416-422.

MacMicking, J.D., Nathan, C., Hom, G., Chartrain, N., Fletcher, D.S., Trumbauer, M., Stevens, K., Xie, Q.W., Sokol, K., Hutchinson, N., et al., 1995. Altered responses to bacterial infection and endotoxic shock in mice lacking inducible nitric oxide synthase. Cell 81, 641-650.

Maren, S., Holt, W.G., 1999. The hippocampus and contextual memory retrieval in Pavlovian fear conditioning. Integr Phys Beh Sci 34, 123-124.

Mark, T.L., Woody, G.E., Juday, T., Kleber, H.D., 2001. The economic costs of heroin addiction in the United States. Drug and alcohol dependence 61, 195-206.

Molero-Chamizo, A., Moron, I., 2015. Latent Inhibition of Conditioned Taste Aversion in Rats With Excitotoxic Dorsal Hippocampal Lesions. Journal of neuroscience research 93, 1740-1747.

Motaghinejad, M., Karimian, S.M., Motaghinejad, O., Shabab, B., Asadighaleni, M., Fatima, S., 2015. The effect of various morphine weaning regimens on the sequelae of opioid tolerance involving physical dependency, anxiety and hippocampus cell neurodegeneration in rats. Fund Clin Pharmacol 29, 299-309.

Nathan, C., Shiloh, M.U., 2000. Reactive oxygen and nitrogen intermediates in the relationship between mammalian hosts and microbial pathogens. Proceedings of the National Academy of Sciences of the United States of America 97, 8841-8848.

Pacheco-Lopez, G., Niemi, M.B., Kou, W., Baum, S., Hoffman, M., Altenburger, P., del Rey, A., Besedovsky, H.O., Schedlowski, M., 2007. Central blockade of IL-1 does not impair taste-LPS associative learning. Neuroimmunomodulation 14, 150-156.

Pacheco-Lopez, G., Niemi, M.B., Kou, W., Harting, M., Fandrey, J., Schedlowski, M., 2005. Neural substrates for behaviorally conditioned immunosuppression in the rat. Journal of Neuroscience 25, 2330-2337.

Paxinos, G., Watson, C., 1998. The rat brain in stereotaxic coordinates. Academic Press, San Diego. 
Perez, L., Lysle, D.T., 1995. Corticotropin-releasing hormone is involved in conditioned stimulus-induced reduction of natural killer cell activity but not in conditioned alterations in cytokine production or proliferation responses. Journal of neuroimmunology 63, 1-8.

Phillips, R.G., Ledoux, J.E., 1994. Lesions of the Dorsal Hippocampal-Formation Interfere with Background but Not Foreground Contextual Fear Conditioning. Learn Memory 1, 34-44.

Redish, A.D., 2001. The hippocampal debate: are we asking the right questions? Behavioural brain research 127, 81-98.

Risdahl, J.M., Khanna, K.V., Peterson, P.K., Molitor, T.W., 1998. Opiates and infection. Journal of neuroimmunology 83, 4-18.

Ross, F.M., Allan, S.M., Rothwell, N.J., Verkhratsky, A., 2003. A dual role for interleukin-1 in LTP in mouse hippocampal slices. Journal of neuroimmunology 144, 61-67.

Sacerdote, P., 2006. Opioids and the immune system. Palliative Med 20, S9-S15.

Sacerdote, P., Franchi, S., Panerai, A.E., 2012. Non-Analgesic Effects of Opioids: Mechanisms and Potential Clinical Relevance of Opioid-Induced Immunodepression. Curr Pharm Design 18, 6034-6042.

Santamaria, L.B., Schifilliti, D., La Torre, D., Fodale, V., 2010. Drugs of anaesthesia and cancer. Surg Oncol 19, 63-81.

Saurer, T.B., Ijames, S.G., Lysle, D.T., 2009. Evidence for the nucleus accumbens as a neural substrate of heroin-induced immune alterations. The Journal of pharmacology and experimental therapeutics 329, 1040-1047.

Schafers, M., Sorkin, L., 2008. Effect of cytokines on neuronal excitability. Neuroscience letters 437, 188-193.

Schedlowski, M., Enck, P., Rief, W., Bingel, U., 2015. Neuro-Bio-Behavioral Mechanisms of Placebo and Nocebo Responses: Implications for Clinical Trials and Clinical Practice. Pharmacological reviews 67, 697-730.

Schedlowski, M., Pacheco-Lopez, G., 2010. The learned immune response: Pavlov and beyond. Brain, behavior, and immunity 24, 176-185.

Schmid, A.W., Lynch, M.A., Herron, C.E., 2009. The effects of IL-1 receptor antagonist on beta amyloid mediated depression of LTP in the rat CA1 in vivo. Hippocampus 19, 670-676.

Schneider, H., Pitossi, F., Balschun, D., Wagner, A., del Rey, A., Besedovsky, H.O., 1998. A neuromodulatory role of interleukin-1beta in the hippocampus. Proceedings of the National Academy of Sciences of the United States of America 95, 7778-7783.

Simonovska, N., Chibishev, A., Bozinovska, C., Grcevska, L., Dimitrovski, K., Neceva, V., 2011. Evaluation of circulating immune complexes and antiphospholipid antibodies (anti beta 2 glycoprotein 1) in heroin addicts and their clinical significance. Medicinski arhiv 65, 324-326. 
Song, P., Zhao, Z.Q., 2001. The involvement of glial cells in the development of morphine tolerance. Neuroscience research 39, 281-286.

Szczytkowski, J.L., Fuchs, R.A., Lysle, D.T., 2011. Ventral tegmental area-basolateral amygdala-nucleus accumbens shell neurocircuitry controls the expression of heroin-conditioned immunomodulation. Journal of neuroimmunology 237, 47-56.

Szczytkowski, J.L., Lebonville, C., Hutson, L., Fuchs, R.A., Lysle, D.T., 2013. Heroin-induced conditioned immunomodulation requires expression of IL-1beta in the dorsal hippocampus. Brain, behavior, and immunity 30, 95-102.

Szczytkowski, J.L., Lysle, D.T., 2007. Conditioned effects of heroin on the expression of inducible nitric oxide synthase in the rat are susceptible to extinction and latent inhibition. Psychopharmacology 191, 879-889.

Szczytkowski, J.L., Lysle, D.T., 2008. Conditioned effects of heroin on proinflammatory mediators require the basolateral amygdala. The European journal of neuroscience 28, 18671876.

Szczytkowski, J.L., Lysle, D.T., 2010. Dopamine D1 receptors within the basolateral amygdala mediate heroin-induced conditioned immunomodulation. Journal of neuroimmunology 226, 3847.

Uehara, E.U., Shida Bde, S., de Brito, C.A., 2015. Role of nitric oxide in immune responses against viruses: beyond microbicidal activity. Inflamm Res 64, 845-852.

United States. National Institute on Drug Abuse, 2014. Research Report Series: Heroin. Department of Health and Human Services, National Institutes of Health, http://www.drugabuse.gov/publications/research-reports/heroin. Accessed 12/17/15.

United States. Substance Abuse and Mental Health Services Administration, 2014. Results from the 2013 National Survey on Drug Use and Health: Summary of National Findings., NSDUH Series H-48. Dept. of Health and Human Services, Substance Abuse and Mental Health Services Administration, Center for Behavioral Health Statistics and Quality, Rockville, MD.

Vallejo, R., de Leon-Casasola, O., Benyamin, R., 2004. Opioid therapy and immunosuppression: a review. American journal of therapeutics 11, 354-365.

Vezzani, A., Viviani, B., 2015. Neuromodulatory properties of inflammatory cytokines and their impact on neuronal excitability. Neuropharmacology 96, 70-82.

von Horsten, S., Exton, M.S., Schult, M., Nagel, E., Stalp, M., Schweitzer, G., Voge, J., del Rey, A., Schedlowski, M., Westermann, J., 1998. Behaviorally conditioned effects of Cyclosporine A on the immune system of rats: specific alterations of blood leukocyte numbers and decrease of granulocyte function. Journal of neuroimmunology 85, 193-201.

Wang, X.H., Loram, L.C., Ramos, K., de Jesus, A.J., Thomas, J., Cheng, K., Reddy, A., Somogyi, A.A., Hutchinson, M.R., Watkins, L.R., Yin, H., 2012. Morphine activates 
neuroinflammation in a manner parallel to endotoxin. Proceedings of the National Academy of Sciences of the United States of America 109, 6325-6330.

Wu, C.L., Benson, A.R., Hobson, D.B., Roda, C.P., Demski, R., Galante, D.J., Page, A.J., Pronovost, P.J., Wick, E.C., 2015. Initiating an Enhanced Recovery Pathway Program: An Anesthesiology Department's Perspective. Joint Commission journal on quality and patient safety / Joint Commission Resources 41, 447-456. 